
KURT BREYSIG

\section{DIE GESCHICHTE DER MENSCHHEIT}

ZWEITER BAND

$\begin{array}{llll}1 & 9 & 3 & 9\end{array}$

WALTER DE GRUYTER \& CO. / BERLIN 


\title{
KURT BREYSIG
}

\section{VÖLKER EWIGER URZEIT}

\author{
NORDLÄNER \\ NORDWESTAMERIKANER \\ NORDOSTAMERIKANER
}

$\begin{array}{llll}1 & 9 & 3 & 9\end{array}$

WALTER DE GRUYTER\& CO. / BERLIN 
Copyright 1939 by Walter de Gruyter \& Co., Berlin

Printed in Germany

Druck von C. Schulze \& Co., G. m. b. H., Gräfenhainichen 


\section{LEWIS HENRY MORGAN}

DEM SCHÖPFER DER NEUEN URZEITWISSENSCHAFT

ZUM GEDÄCHTNIS 
